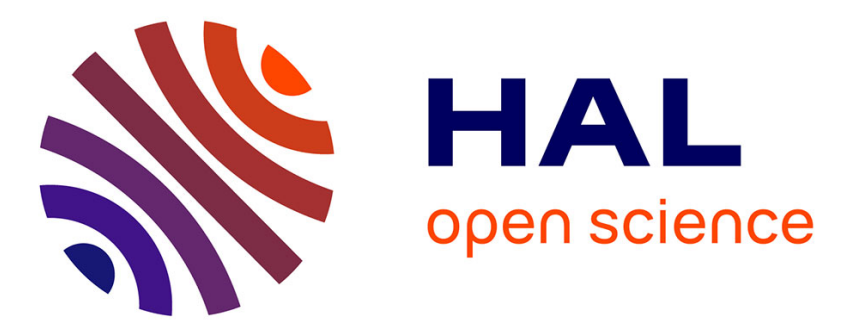

\title{
A microfluidic device for digital manipulation of gaseous samples
}

\author{
A. Enel, A. Bourrelier, J. Vial, Didier Thiebaut, B. Bourlon
}

\section{To cite this version:}

A. Enel, A. Bourrelier, J. Vial, Didier Thiebaut, B. Bourlon. A microfluidic device for digital manipulation of gaseous samples. Lab on a Chip, 2020, 20 (7), pp.1290-1297. 10.1039/C9LC01163C . hal-03064972

\section{HAL Id: hal-03064972 \\ https://hal.science/hal-03064972}

Submitted on 14 Dec 2020

HAL is a multi-disciplinary open access archive for the deposit and dissemination of scientific research documents, whether they are published or not. The documents may come from teaching and research institutions in France or abroad, or from public or private research centers.
L'archive ouverte pluridisciplinaire HAL, est destinée au dépôt et à la diffusion de documents scientifiques de niveau recherche, publiés ou non, émanant des établissements d'enseignement et de recherche français ou étrangers, des laboratoires publics ou privés. 


\title{
A microfluidic device for digital manipulation of gaseous samples
}

\author{
A. Enel ${ }^{1}$, A. Bourrelier ${ }^{1}$, J. Vial $^{2}$, D. Thiébaut ${ }^{2}$, and B. Bourlon ${ }^{1}$ \\ ${ }^{1}$ Univ. Grenoble Alpes, CEA, LETI, MINATEC Campus, F-38000 Grenoble, France \\ ${ }^{2}$ UMR8231 CBI, LSABM, ESPCI Paris-CNRS, PSL Institute, Paris, France \\ E-mail: bertrand.bourlon@cea.fr
}

\section{Abstract}

Digital microfluidics is known for fine manipulation of sub-millimeter samples, with applications from biological sample preparation to diagnostic testing. Unfortunately, until now, it is only limited to liquid phases. In this paper, we present a new system based on a digital microfluidic platform (DMFP), which is able to digitally manipulate gaseous samples, such as alkanes from $n$-hexane to $n$-nonane. The DMFP relies mostly on interconnected micropreconcentrators $(\mu \mathrm{PC})$ to trap and release the samples depending on their controlled temperature. We show that the DMFP is capable to perform all basic operations of digital microfluidics: trapping/releasing and moving samples, adding samples and separating samples, i.e. making a substraction. As a first example of more complex programmable use of our DMFP, we measured the breakthrough volume of alkanes on Tenax TA adsorbent. The results were consistent with tabulated values obtained with standard laboratory instruments. Such DMFP promises great possibilities for more complex programmable gas microfluidics digital devices and the development of new digital gas sample preparation and analysis methods.

\section{Keywords}

Digital microfluidics; gas samples preparation and analysis; silicon microfabrication; miniaturization; preconcentrator

\section{Introduction}

Over the past decade, microfluidics, defined as the manipulation of fluids at small scale, mainly submillimeter scale, have steadfastly progressed ${ }^{1-12}$. It is also compounded by the understanding of the fluid mechanics at this scale, the chemical interactions and the microfabrication techniques mandatory to craft these devices. The development of microfluidics has yielded several techniques of small-scale fluid control, for example efficient and reproducible droplet generation by making two immiscible liquids flow through specific shapes. This technique is very useful: droplets are almost a closed medium, as diffusion to the surrounding fluid is very low, and allows for encapsulation of useful substances, such as enzymes for enzymatic assays ${ }^{13}$. Another technique emerged, among lots of others: electrowetting, more specifically electrowetting on a dielectric (EWOD). In this mode, two electrodes are used to create an electric field on a dielectric, which changes the wettability of the dielectric and so the contact angle of the droplet. This change allows for movement or immobilization of the droplet. It is then possible to make a grid with these electrodes, and move droplets at will on this grid. These two techniques paved the way for digital microfluidics: microfluidics programmable by analogy to a digital computer. This means that the droplets are commanded by a set of simple instructions, from known state to known state while a clock is used to synchronize the system. This leads to several operations such as moving, trapping, mixing or merging, storing, and extraction of samples. Most of these devices use liquid phases samples, mostly droplets in an immiscible 
surrounding fluid. Several devices also use bubbles surrounded by liquid ${ }^{14,15}$. To our knowledge, no digital microfluidic device has been made to manipulate gas samples within a carrier gas.

In the meantime, developments in miniaturization of air analysis devices have yielded micropreconcentrators ${ }^{16-18}(\mu \mathrm{PC})$. These devices consist of a chamber containing an adsorbent, a heating element and a temperature probe. It is then possible to trap a gas on the adsorbent, or release it at will by changing the $\mu \mathrm{PC}$ temperature. When the compound of interest is trapped on the $\mu \mathrm{PC}$, it does not diffuse within the surrounding gas. These characteristics make $\mu \mathrm{PC}$ a suitable building block for digital microfluidics. Digital microfluidics for gases could help to design programmable, automatic and versatile gas sample preparation and analysis systems. These systems could be free from diffusion related issues that are met in conventional instruments ${ }^{19}$. They could also allow sample manipulation without losses. As applications, such devices could be combined with conventional analytical techniques or open new approaches for portable miniaturized instruments.

In this work, a digital microfluidic platform (DMFP) using pumps, $\mu \mathrm{PC}$ and a detector was assembled. We showed that the digital manipulation of gas samples was possible with the DMFP, and demonstrated all elementary operations: trapping/releasing and moving a compound, merging two compounds and separating two compounds. Several alkanes, ranging from $n$-hexane (C6) to n-nonane (C9) were used to demonstrate these operations. These elementary operations were carried-out by controlling precisely, step by step, the state of the pumps and the temperature of the $\mu$ PCs. These elementary operations were also the first step towards a more complex device, which could be used to perform high-level functions, such as separation of mixed samples.

As a first proof of concept of a more complex programmable application, the DMFP was used to measure the breakthrough volume of these alkanes on a classical adsorbent (Tenax TA). Breakthrough volume measurements with standard laboratory instruments, such as a gas chromatograph, are labor intensive, as they need several injections, one for each temperature studied. As an illustration of potential applications, it was possible to measure automatically with the DMFP the breakthrough volume on a wide range of temperatures using only one injection, by manipulating without loss the same initial gas sample.

\section{Experimental}

\section{Components fabrication}

The micropreconcentrator chip fabrication has been already described elsewhere ${ }^{20,21}$. The size of the $\mu P C$ chip was $21 \mathrm{~mm} \times 7.6 \mathrm{~mm}$. On the front side of the silicon chip, $400 \mu \mathrm{m}$ deep inlet/outlet and a central cavity were etched in silicon, and sealed with a Pyrex glass. The $6.6 \mu \mathrm{L}$ cavity was filled with Tenax-TA adsorbent powder, a polymer of 2,6-diphenylphenol. Tenax TA is widely used for trapping volatile organic compounds from air samples. Inlet/outlet of the chip were glued to nickel capillaries. On the back side of the chip Ti/Pt thin film heaters and thermoresistive probes were deposited. Several other similar designs have been reported in the literature ${ }^{22-24}$.

The micro thermal conductivity detectors ( $\mu T C D$ ) were also batch processed on $200 \mathrm{~mm}$ silicon wafers. The size of the $\mu$ TCD chip was $9.6 \mathrm{~mm} \times 5.4 \mathrm{~mm}$. Two $100 \mu \mathrm{m}$ deep $200 \mu \mathrm{m}$ wide microchannels were etched in the silicon chip by anisotropic deep reactive ion etching (DRIE) following by isotropic plasma etching. Each channel contained two suspended membranes. Each membrane was made of $200 \mathrm{~nm}$ thin silicon nitride membrane on which a platinum thermoresistive conductor had been deposited by sputtering. The other half of microchannels was etched by wet etching on a Pyrex glass that was finally sealed on top of the silicon wafer. The $\mu$ TCD was then glued and wire-bonded to a printed circuit board 
holder. $80 \mu \mathrm{m}$ inner diameter and $150 \mu \mathrm{m}$ outer diameter fused silica capillaries were then glued in the inlets/outlets of the silicon chip microchannels. The membranes were then connected electrically in a Wheatstone bridge structure. Several similar other designs have been reported in the literature ${ }^{25,26}$.

When the $\mu T C D$ is functioning, the membranes are heated and thermal exchanges with the surrounding gas reach a stationary state. If the surrounding gas changes its thermal conductivity, for example by changing its chemical composition, the thermal exchanges are disrupted. This causes the membranes to change their temperatures, and their resistance. This changes the output of the Wheatstone bridge, which is monitored. The $\mu T C D$ output is then related to the concentration of the sample inside the carrier gas. When samples go through the $\mu T C D$, the resulting signal has the shape of a peak. The peak's height is related to the concentration of the sample, and its area to the amount of sample.

The $\mu T C D$ was checked for linearity: as expected, the area of the peaks scaled linearly with the amount of sample within the studied range. The results are available in the supplementary data.

\section{Experimental setup}

The schematics of the DMFP are presented in Figure 1.
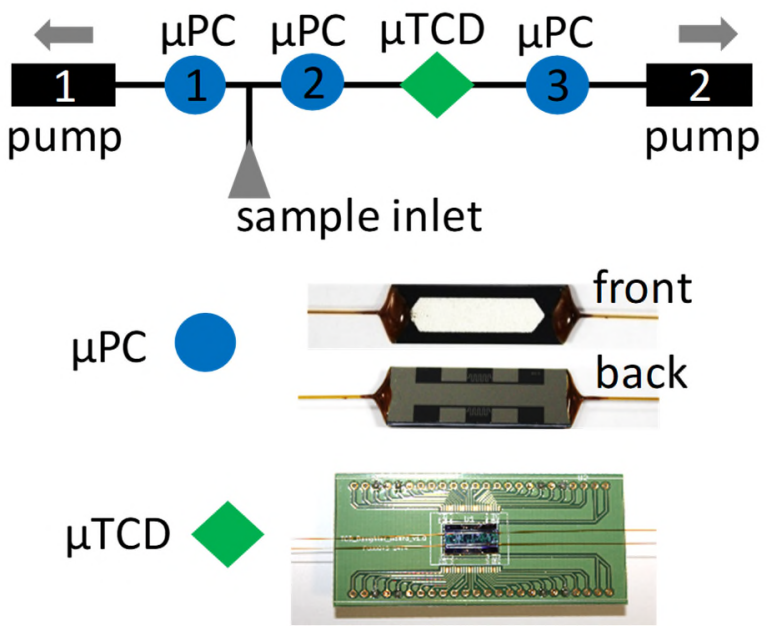

Figure 1 : DMFP schematics and pictures of the elementary bricks. The arrows indicate flow direction.

As shown on Figure 1, the DMFP contained three $\mu P C$ and one $\mu T C D$, with two pumps linked to them. The pumps were not miniaturized, but the main building bricks of the system were. The pumps may be miniaturized in the future, as such pumps have already been reported ${ }^{27}$. No valves were used here, however miniaturized valves have been reported ${ }^{28}$. Pumps were Xavitech models (V200-O2C12V) and connected to the DMFP with Tygon ${ }^{\circledR}$ tubes $\left(1 / 6^{\prime \prime}\right.$ outer diameter, $1 / 10^{\prime \prime}$ inner diameter). The carrier gas used to move samples inside the DMFP was ambient air. 1/16" unions were used to connect the components together, with $1 / 16^{\prime \prime}$ ferrules and nuts. The $\mu$ TCD was connected between the $\mu$ PC2 and $\mu P C 3$ using one of its two gas channels (as analytical channel); the second $\mu$ TCD gas channel was connected between $\mu \mathrm{PC} 3$ and pump 2 (as reference channel) to lower the baseline drift. The second reference connection is not shown in the Figure 1 for simplification. A fused silica capillary, $1.50 \mathrm{~m} \mathrm{x}$ $250 \mu \mathrm{m}$ inner diameter, was used to connect the $\mu \mathrm{PC} 2$ to the $\mu \mathrm{TCD}$. This capillary was found to reduce 
artefacts on the $\mu \mathrm{TCD}$ signal. The artefacts were caused by transitory states during the heating of a $\mu P C$ or the pumps starting. They appeared close to the sample peak, disturbing the baseline. The pumps and $\mu \mathrm{PC}$ were powered by a $12 \mathrm{~V}$ supply device, and the $\mu \mathrm{TCD}$ by a $9 \mathrm{~V}$ battery. An electronic setup connected to a computer through USB allowed to control the pumps, the $\mu \mathrm{PC}$ heaters as well as to acquire signal from the $\mu T C D$ and the $\mu P C$ temperature probes. Labview 2012 was used to program and control the sequence of states of the DMFP, as well as acquire and register the data.

Samples could be injected on either $\mu \mathrm{PC} 1$ or $\mu \mathrm{PC} 2$ by pumping with pump 1 or pump 2 respectively. Samples were prepared by injecting a few microliters of liquid sample inside a Tedlar $^{\circledR}$ bag of $1 \mathrm{~L}$ (Supelco, 24633) filled with 5.0 nitrogen (Air Liquide). The samples used were $n$-hexane (C6) (Carlo Erba, 99\% HPLC grade), n-heptane (C7) (99\% anhydrous, Sigma Aldrich), n-octane (C8) ( $\geq 99 \%$ anhydrous, Sigma Aldrich) and n-nonane (C9) ( $\geq 99 \%$ anhydrous, Sigma Aldrich). Prior to injection, the bag was cleaned by filling it 3 times with 5.0 nitrogen and emptying with a vacuum pump. After injection of the sample in the bag, the bag was let at room temperature for 15 minutes to equilibrate. For the injection of samples, the Tedlar ${ }^{\circledR}$ bag was connected to the inlet of the T-junction. The connection was made with a 1/16" stainless steel capillary. Several samples were prepared: C6 5 ppm, C7 10 ppm, C7 5 ppm, C9 5 ppm, C7-C9 5 ppm, C6 1 ppm, C7 1 ppm, C8 1 ppm, C9 1 ppm. Mass flow rates inside the DMFP were around $0.30 \mathrm{~mL} / \mathrm{min}$.

\section{Results and discussion}

The manipulation of gaseous samples relies mostly on the adsorption/desorption of compounds using adsorbent packed in the $\mu \mathrm{PC}$. The compounds are trapped on the adsorbent and released when the $\mu \mathrm{PC}$ is heated. Using pumps, it is possible to control the gas flow and thus the samples displacement.

\section{Trapping and preconcentration}

The ability of our $\mu \mathrm{PC}$ to trap compounds was checked using n-hexane ( $5 \mathrm{ppm}$ ). $\mathrm{C} 6$ was first loaded on $\mu \mathrm{PC} 2$ before starting the experiment. Table 1 presents the DMFP program used for this experiment.

\begin{tabular}{l|l|l|l|l|l|l} 
& $\begin{array}{l}\mu \mathrm{PC} 1 \\
\text { temperature } \\
\left({ }^{\circ} \mathrm{C}\right)\end{array}$ & $\begin{array}{l}\mu \mathrm{PC} 2 \\
\text { temperature } \\
\left({ }^{\circ} \mathrm{C}\right)\end{array}$ & $\begin{array}{l}\mu \mathrm{PC} 3 \\
\text { temperature } \\
\left({ }^{\circ} \mathrm{C}\right)\end{array}$ & $\begin{array}{l}\text { Pump } \\
1 \text { state }\end{array}$ & $\begin{array}{l}\text { Pump 2 } \\
\text { state }\end{array}$ & $\begin{array}{l}\text { Duration } \\
(\mathrm{s})\end{array}$ \\
Step 1 & Ambient & 150 & Ambient & OFF & ON & 60 \\
Step 2 & Ambient & Ambient & Ambient & ON & OFF & 15 \\
Step 3 & 150 & 150 & Ambient & OFF & ON & 120 \\
Step 4 & Ambient & Ambient & 150 & ON & OFF & 120
\end{tabular}

Table 1 : Program of the DMFP used for the preconcentration experiment. On every step 2 a Tedlar bag containing C6 in nitrogen was connected to the injector to load C6 on $\mu P C 1$.

On step 1, the sample moved from $\mu \mathrm{PC} 2$ to $\mu \mathrm{PC} 3$. On step 2, the Tedlar bag containing $\mathrm{C} 65 \mathrm{ppm}$ was plugged to the injector: supplementary $\mathrm{C} 6$ was loaded on $\mu \mathrm{PC} 1$. The bag was then plugged out and the injector closed. On step 3, the supplementary $\mathrm{C} 6$ moved from $\mu \mathrm{PC} 1$ to $\mu \mathrm{PC} 3$. On step 4, the sample moved to $\mu \mathrm{PC} 2$.

Results are shown on Figure 2. 


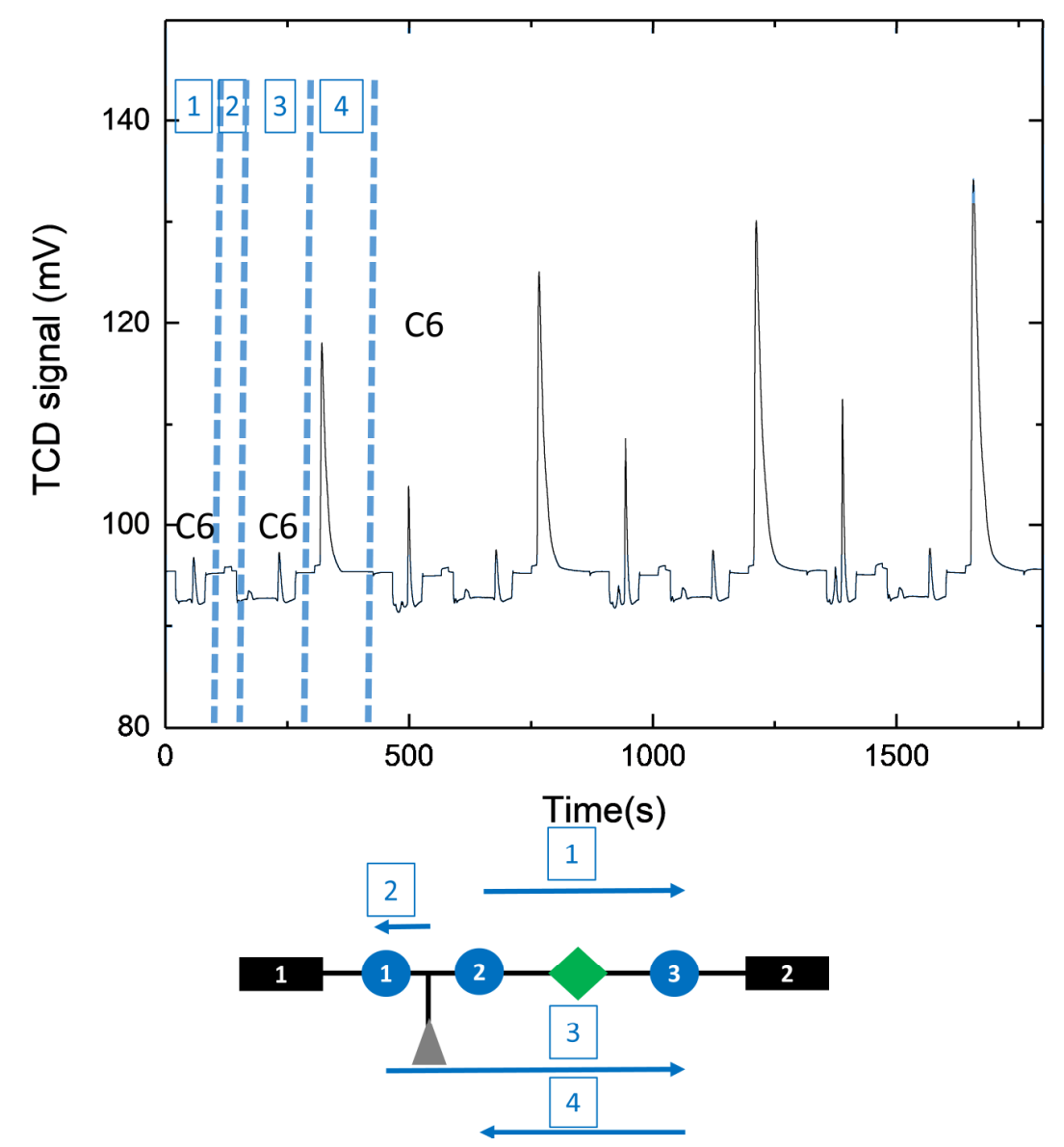

Figure 2 : Concentration of 5 ppm n-hexane in nitrogen on $\mu P C 2$.The 4 steps are indicated by the numbers on the figure: Step 1 was the movement of the sample from $\mu P C 2$ to $\mu P C 3$. Step 2 was the loading of the sample on $\mu P C 1$. Step 3 was the movement of the sample from $\mu P C 1$ to $\mu P C 3$. Step 4 was the movement of the sample from $\mu P C 3$ to $\mu P C 2$. Step 1,2,3,4 were repeated 4 times in total. Each time the compound went through the $\mu T C D$ a signal (peak) is produced. The height of the C6 peak increased on every cycle, meaning C6 was effectively being concentrated.

As shown in Figure $2, \mu \mathrm{PCs}$ are very effective at concentrating compounds, trapping them and releasing them on demand. During each step 3, the height and area of the C6 peak was the same, indicating the amount of $\mathrm{C} 6$ loaded during step 2 was constant. During each step 1 and step 4, the height and area of the $n$-hexane peak rose, meaning the amount of C6 trapped on $\mu$ PC3 was increasing. This is consistent with the fact that $\mathrm{C} 6$ was trapped on the $\mu \mathrm{PC} 3$ and could be released on demand, and that more $\mathrm{C} 6$ was added to the DMFP at each step 2.

The sample, C7 (10 ppm), was loaded on $\mu \mathrm{PC} 2$, and then moved back and forth 20 times between $\mu \mathrm{PC} 2$ and $\mu$ PC3. Table 2 shows the DMFP program used for this experiment. It consisted of two steps: step 1 consisted in heating $\mu \mathrm{PC} 2$ with pump 2 on: the sample was carried to $\mu \mathrm{PC} 3$. Step 2 consisted in heating $\mu \mathrm{PC} 3$ with pump 1 on: the sample was carried to $\mu \mathrm{PC} 2$. 


\begin{tabular}{|c|c|c|c|c|c|c|}
\hline & $\begin{array}{l}\mu \mathrm{PC} 1 \\
\text { temperature } \\
\left({ }^{\circ} \mathrm{C}\right)\end{array}$ & $\begin{array}{l}\mu \mathrm{PC} 2 \\
\text { temperature } \\
\left({ }^{\circ} \mathrm{C}\right)\end{array}$ & $\begin{array}{l}\mu \mathrm{PC} 3 \\
\text { temperature } \\
\left({ }^{\circ} \mathrm{C}\right)\end{array}$ & $\begin{array}{l}\text { Pump } \\
1 \text { state }\end{array}$ & $\begin{array}{l}\text { Pump } 2 \\
\text { state }\end{array}$ & $\begin{array}{l}\text { Duration } \\
\text { (s) }\end{array}$ \\
\hline Step 1 & Ambient & 150 & Ambient & OFF & ON & 30 \\
\hline Step 2 & Ambient & Ambient & 150 & ON & OFF & 30 \\
\hline
\end{tabular}

Table 2 : Program of the DMFP used for the controlled movements experiment.

Figure 3 shows the TCD signal collected during a sequence of 20 movements of the sample.
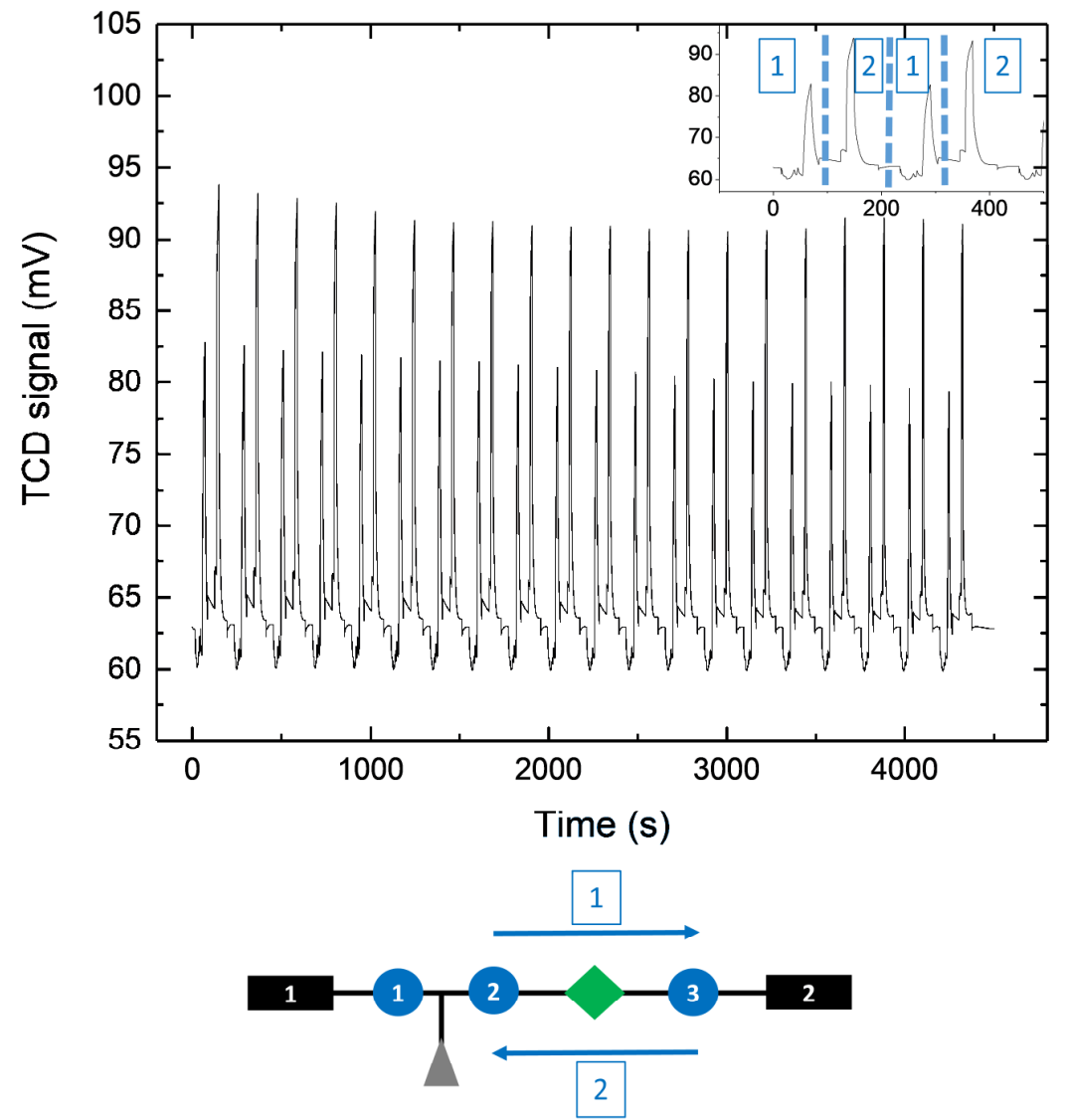

Figure 3 : Controlled movement of n-heptane 10 ppm between $\mu P C 2$ and $\mu P C 3$. Two steps were done: on step 1, $\mu P C 2$ was heated to $150^{\circ} \mathrm{C}$ for $30 \mathrm{~s}$ and $n$-heptane went to $\mu P C 3$. $\mu P C 2$ cooled down for $40 \mathrm{~s}$. On step 2, $\mu P C 3$ was heated to $150^{\circ} \mathrm{C}$ and $n$-heptane went to $\mu P C 2$. $\mu P C 3$ cooled down for 40s. See the inset for a more detailed view of the steps. Steps 1 and 2 were then repeated 20 times. A signal peak was observed every time n-heptane went through the $\mu T C D$.

Figure 3 shows that the sample could be moved 20 times without significant losses over time due to diffusion, or non-efficient trapping. Indeed, the peaks obtained during the 20 steps 1 looked similar, with an area distribution of $4583 \pm 683 \mathrm{mV}^{*}$. The peaks obtained during the 20 steps 2 also looked similar: their area distribution was $7063 \pm 1226 \mathrm{mV}^{*}$ s. This means the $\mu \mathrm{PC}$ was effective at trapping compounds, and managed to release them efficiently when heated. However, one can notice a slight variation in the height of the peaks obtained during step 1 and the height of the peaks obtained during step 2 was observed, certified by a statistical test. This variation could be attributed to the fused silica capillary between PC2 and the $\mu \mathrm{TCD}$ : its volume was $75 \mu \mathrm{L}$, compared to the $1.5 \mu \mathrm{L}$ capillary volume between PC3 and the $\mu \mathrm{TCD}$. The sample diffused more when traveling through the $75 \mu \mathrm{L}$, causing a 
decrease in local concentration and thus a decrease in the $\mu$ TCD peak signal. The amplitude of this variation was low and did not hinder the conclusions. This could be investigated and solved in a future setup if needed.

\section{Mixing two different compounds}

It was also possible to use this device to mix two compounds. To demonstrate this, $\mu \mathrm{PC} 1$ and $\mu \mathrm{PC} 2$ were loaded with C9 (5 ppm) with C7 (5 ppm), respectively. The compounds were added on $\mu \mathrm{PC} 3$ and then moved back and forth between $\mu \mathrm{PC} 2$ and $\mu \mathrm{PC} 3$. The Table 3 shows the DMFP program used for this experiment.

\begin{tabular}{l|l|l|l|l|l|l} 
& $\begin{array}{l}\mu P C 1 \\
\text { temperature } \\
\left({ }^{\circ} \mathrm{C}\right)\end{array}$ & $\begin{array}{l}\mu \mathrm{PC} 2 \\
\text { temperature } \\
\left({ }^{\circ} \mathrm{C}\right)\end{array}$ & $\begin{array}{l}\mu \mathrm{PC} 3 \\
\text { temperature } \\
\left({ }^{\circ} \mathrm{C}\right)\end{array}$ & $\begin{array}{l}\text { Pump } \\
1 \text { state }\end{array}$ & $\begin{array}{l}\text { Pump 2 } \\
\text { state }\end{array}$ & $\begin{array}{l}\text { Duration } \\
(\mathrm{s})\end{array}$ \\
Step 1 & Ambient & 150 & Ambient & OFF & ON & 180 \\
Step 2 & 150 & 150 & Ambient & OFF & ON & 360 \\
Step 3 & Ambient & Ambient & 150 & ON & OFF & 120 \\
Step 4 & Ambient & 150 & Ambient & OFF & ON & 120 \\
Step 5 & Ambient & Ambient & 150 & ON & OFF & 120
\end{tabular}

\section{Table 3 : Program used for the C7-C9 addition experiment.}

The results are shown on Figure 4.

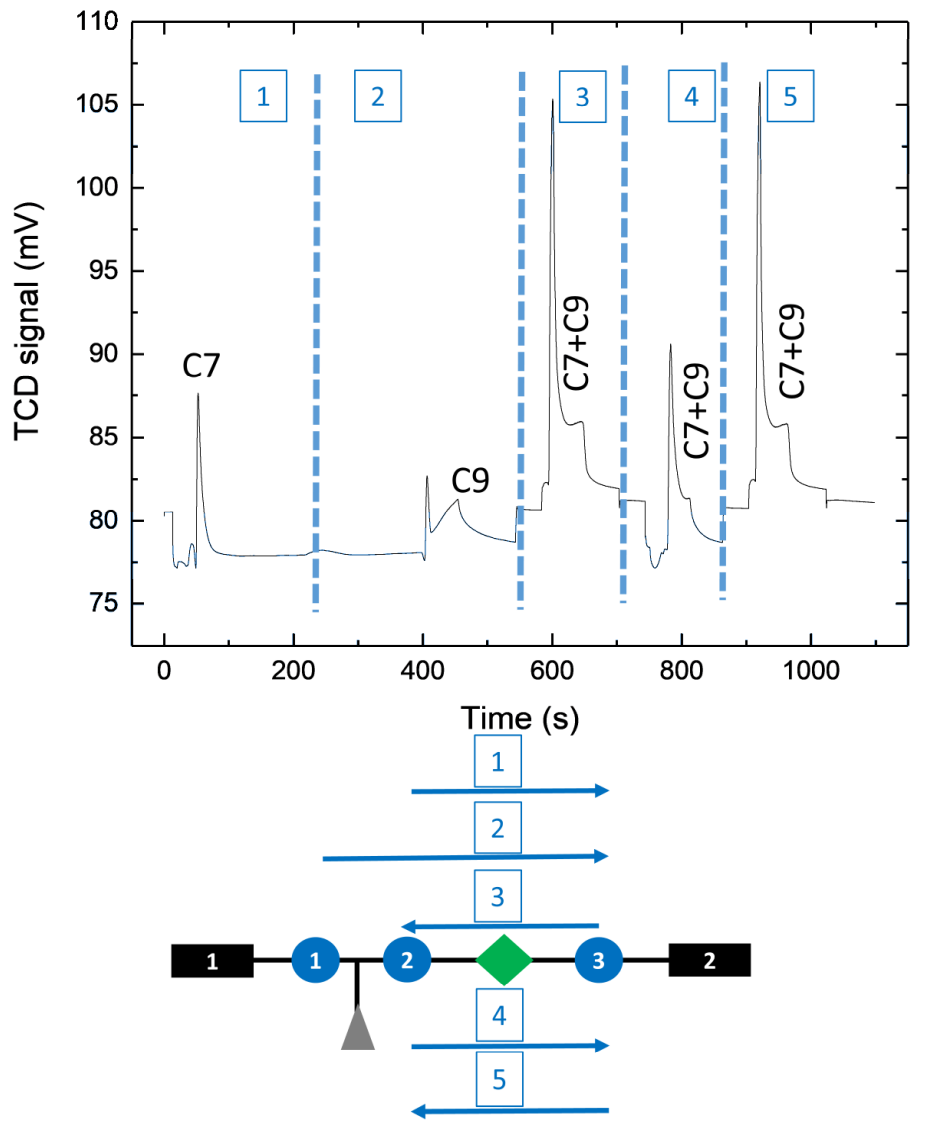



and 5: they did not separate on their own.

\section{Separating different compounds} for this experiment is shown in Table 4.

Figure 4 : Addition of $\mathrm{n}$-heptane $5 \mathrm{ppm}$ with $\mathrm{n}$-nonane $5 \mathrm{ppm}$. The peaks are labelled on the figure. Each time a compound went through the $\mu T C D$ a signal peak was observed. The peaks observed at $600 \mathrm{~s}, 800 \mathrm{~s}$ and $900 \mathrm{~s}$ were a combination of the peaks observed at $80 \mathrm{~s}(\mathrm{C} 7)$, and the peak observed at $480 \mathrm{~s}$ (C9). To move compounds, the $\mu \mathrm{PC}$ s were heated to $150^{\circ} \mathrm{C}$.

Figure 4 shows that the two compounds, $\mathrm{C7}$ and C9, produced, visually, different peaks when they went through the $\mu T C D$. C7 went through the $\mu T C D$ on step 1; C9 went through on step 2. On step 3 both of them were added on $\mu \mathrm{PC} 3$, the resulting peak being the sum of the two individual peaks. This meant that the addition was successful, and the two compounds could move together during steps 4

Using the DMFP it was also possible to separate two different compounds. To show this, C7-C9 5 ppm was loaded on $\mu \mathrm{PC} 1$, and then moved on $\mu \mathrm{PC} 3$ during a preliminary step, which is not shown.

A three-step procedure was then performed: on step $1, \mu \mathrm{PC} 2$ and $\mu \mathrm{PC} 3$ were heated to $180^{\circ} \mathrm{C}$ : the sample moved from $\mu \mathrm{PC} 3$ to $\mu \mathrm{PC} 1$. On step $2, \mu \mathrm{PC} 2$ was set to $115^{\circ} \mathrm{C}$ and the mix $\mathrm{C} 7-\mathrm{C} 9$ moved from $\mu \mathrm{PC} 1$ to $\mu \mathrm{PC} 3$. As the mix went through $\mu \mathrm{PC} 2$, the separation was performed: $115^{\circ} \mathrm{C}$ was hot enough for $\mathrm{C} 7$ to move through, but too cold for $\mathrm{C} 9$, which was not volatile enough to be displaced. C9 was trapped on $\mu \mathrm{PC2}$. On step $3, \mu \mathrm{PC} 2$ was then heated to $180^{\circ} \mathrm{C}$ to release $\mathrm{C}$. The DMFP program used

\begin{tabular}{l|l|l|l|l|l|l} 
& $\begin{array}{l}\mu \mathrm{PC} 1 \\
\text { temperature } \\
\left({ }^{\circ} \mathrm{C}\right)\end{array}$ & $\begin{array}{l}\mu \mathrm{PC} 2 \\
\text { temperature } \\
\left({ }^{\circ} \mathrm{C}\right)\end{array}$ & $\begin{array}{l}\mu \mathrm{PC} 3 \\
\text { temperature } \\
\left({ }^{\circ} \mathrm{C}\right)\end{array}$ & $\begin{array}{l}\text { Pump } \\
1 \text { state }\end{array}$ & $\begin{array}{l}\text { Pump 2 } \\
\text { state }\end{array}$ & $\begin{array}{l}\text { Duration } \\
(\mathrm{s})\end{array}$ \\
Step 1 & Ambient & 180 & 180 & ON & OFF & 180 \\
Step 2 & 180 & 115 & Ambient & OFF & ON & 120 \\
Step 3 & Ambient & 180 & Ambient & OFF & ON & 120
\end{tabular}



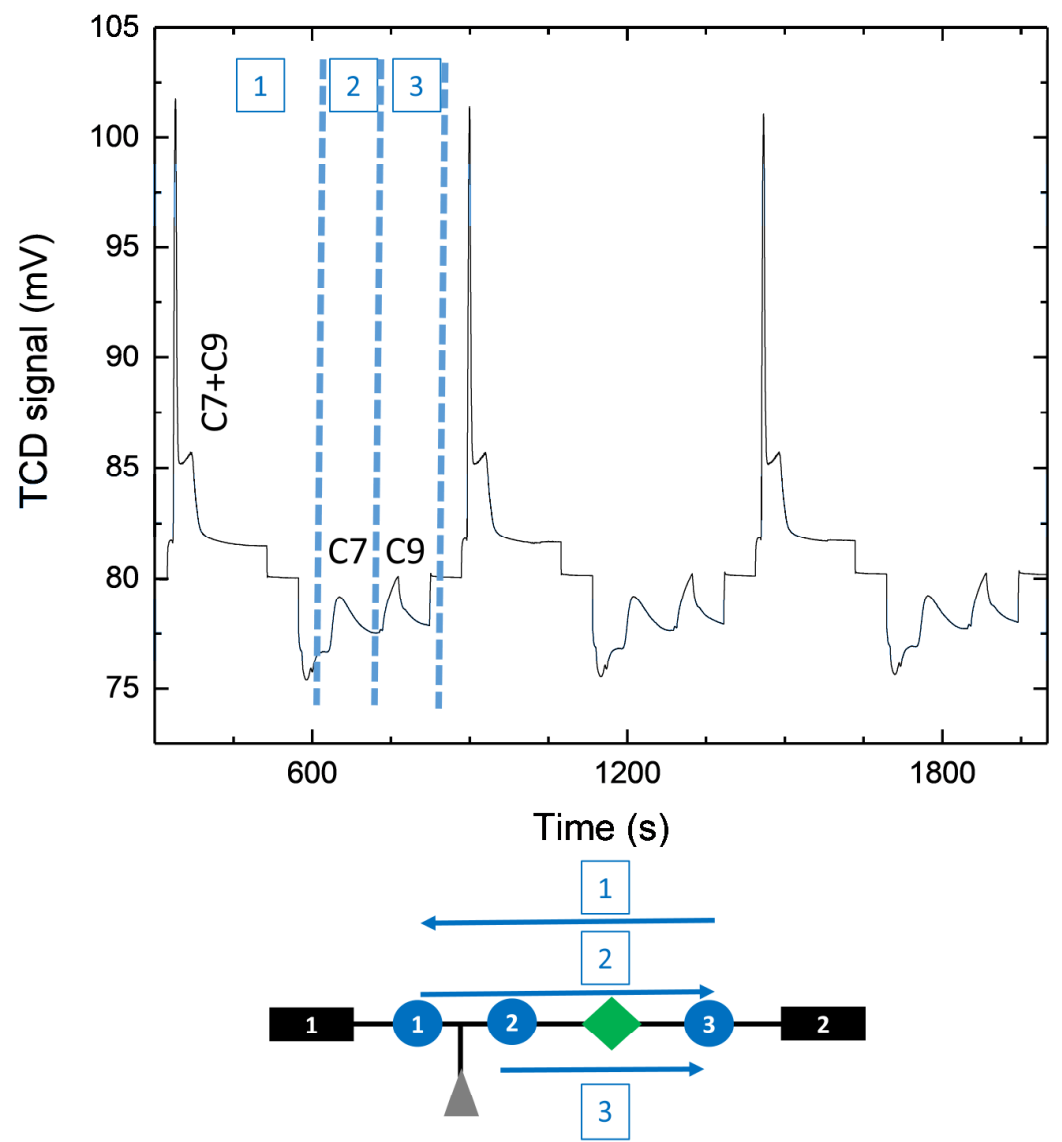

Figure 5: Separation of $C 7$ and $C 9 . C 7$ and $C 9$ were first loaded on $\mu P C 1$. A preliminary step was done to move the sample from $\mu P C 1$ to $\mu P C 3$. This step is not shown. Three steps were done: on step 1, the C7-C9 mix was pumped to $\mu P C 1, \mu P C 2$ and $\mu P C 3$ were heated to $180^{\circ} \mathrm{C}$. On step $2, \mu P C 2$ was set to $115^{\circ} \mathrm{C}$ and the mix went to $\mu P C 2.115^{\circ} \mathrm{C}$ was hot enough for $C 7$ to go through $\mu P C 2$ and not be trapped: it went through the $\mu T C D$ to $\mu P C 3$. C9 is not volatile enough and was trapped on $\mu P C 2$. On step 3, $\mu P C 2$ was heated to $180^{\circ} \mathrm{C}$ : C9 was released and went to $\mu P C 3$ through the $\mu T C D$. Steps 1, 2 and 3 were then repeated twice.

229 Figure 5 shows that the separation was effective: by keeping $\mu \mathrm{PC} 2$ at $115^{\circ} \mathrm{C} C 7$ was able to go through but $\mathrm{C} 9$ was trapped. $\mathrm{C} 9$ was only released by heating $\mu \mathrm{PC} 2$ at $180^{\circ} \mathrm{C}$. Three successive successful separations showed the process was repeatable. As co-elutions between $\mathrm{C} 7$ and $\mathrm{C} 9 \mathrm{might}$ be possible, 
control experiments were done by analysing C7 5 ppm and C9 5 ppm with the same program shown in Table 4. Results are shown on Figure 6.

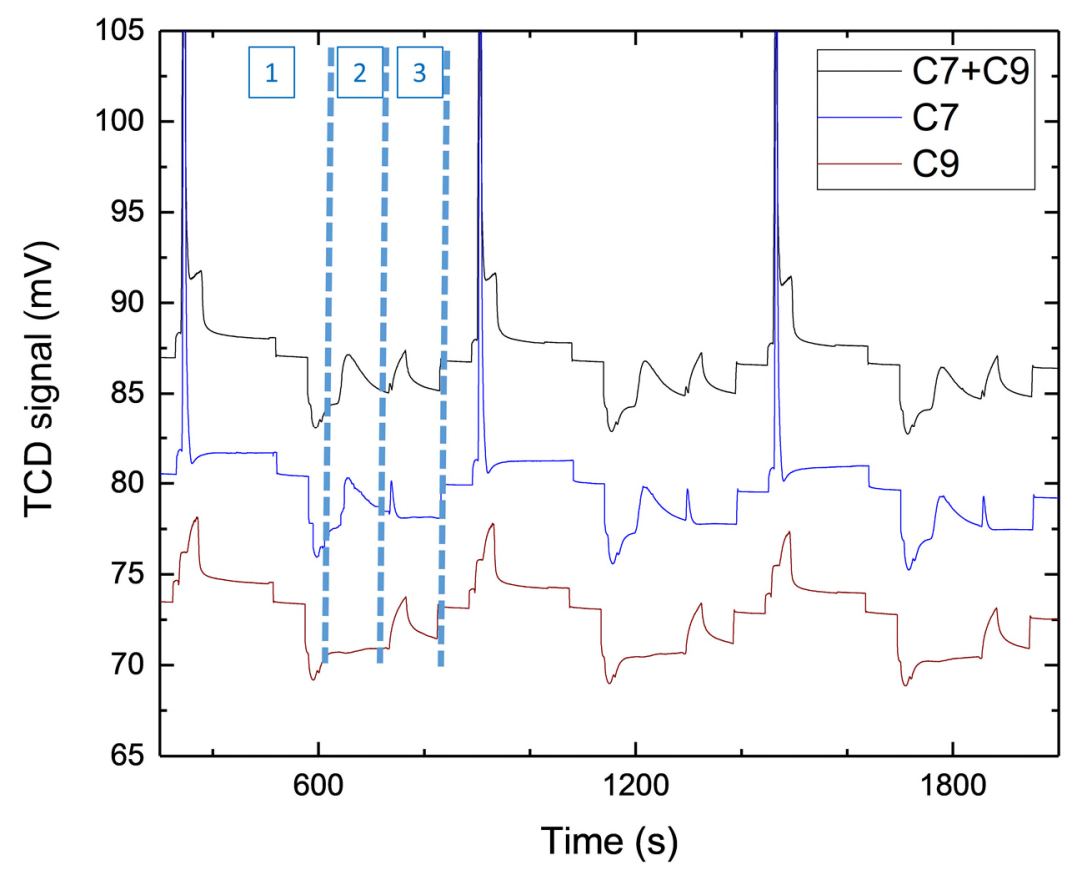

Figure 6: Separation of C7 5 ppm and C9 5 ppm. The program is the same as shown on Table 4. For the black trace, both C7 5 ppm and C9 5 ppm were loaded on $\mu$ PC1. For the blue trace, only C7 5 ppm was loaded. For the red trace, only C9 5 ppm was loaded.

Figure 6 shows that the separation was quite effective, as C9 was totally trapped on $\mu P C 2$ during step 2. However, the separation was not complete: a small amount of $C 7$ went through the $\mu$ TCD during step 3, meaning it was trapped on $\mu \mathrm{PC} 2$ during step 2. By measuring the peak area, around $11 \%$ of the total $\mathrm{C7}$ amount was trapped on $\mu \mathrm{PC} 2$ during step 2 and $89 \%$ of the amount went through. The DMFP could not perform a perfect single-step separation, but it is still capable of separating different compounds, which is one of the basics operations of digital microfluidics. The performances could be enhanced by repeating the separation step.

\section{Measuring breakthrough volumes}

The DMFP was used to measure breakthrough volumes (BV) on $n$-alkanes ranging from $n$-hexane to $n$ nonane (C9). With standard laboratory instruments, BV studies requires multiple samplings, injections and analyses, as the sample is lost after each analysis. The DMFP used the same sample that was digitally manipulated to gather in about 10 minutes the data needed for one BV measurement at a specific temperature. As the BV was assessed automatically for one compound with the DMFP on a wide range of temperatures in one experiment, the experiment duration was about 3 hours. The BV is the volume of carrier gas needed to elute $50 \%$ of the analyte through the adsorbent, at a specific temperature. It is expressed in liters/grams of adsorbent. The BV is an intrinsic value, which can be tabulated. It characterizes the strength of the interaction between one compound and one adsorbent. At constant flow rate of carrier gas, the BV only changes with temperature for a couple analyte/adsorbent: as temperature increases, the BV decreases due to the adsorption equilibrium shifting towards the desorption of the analyte. The BV tables are useful to assess which adsorbent to use for a specific target, and the range of temperatures in which the target is trapped or released. 
During these experiments, the sample was loaded on $\mu \mathrm{PC} 1$. The experiments then consisted in two steps: at step $1, \mu \mathrm{PC} 1$ was heated to $150^{\circ} \mathrm{C}$ and $\mu \mathrm{PC} 2$ to a selected temperature, ranging from $150^{\circ} \mathrm{C}$ to $70^{\circ} \mathrm{C}$. Pump 2 was switched on for $300 \mathrm{~s}$. At step $2, \mu \mathrm{PC} 3$ and $\mu \mathrm{PC} 2$ were heated to $150^{\circ} \mathrm{C}$. Pump 1 was switched on for $60 \mathrm{~s}$. Every time step 1 was repeated, $\mu \mathrm{PC} 2$ temperature was lowered by $5^{\circ} \mathrm{C}$. Table 5 shows the DMFP program used for this experiment.

\begin{tabular}{l|l|l|l|l|l|l}
$\mu \mathrm{PCC} 1$ & $\mu \mathrm{PC2}$ & $\mu \mathrm{PC} 3$ & $\begin{array}{l}\text { Pump } \\
\text { temperature } \\
\left({ }^{\circ} \mathrm{C}\right)\end{array}$ & $\begin{array}{l}\text { temperature } \\
\left({ }^{\circ} \mathrm{C}\right)\end{array}$ & $\begin{array}{l}\text { Pump 2 } \\
\left({ }^{\circ} \mathrm{C}\right)\end{array}$ & $\begin{array}{l}\text { Duration } \\
\text { state }\end{array}$ \\
Step 1 & 150 & $150-70$ & Ambient & OFF & ON & 300 \\
Step 2 & Ambient & 150 & 150 & ON & OFF & 60
\end{tabular}

Table 5 : DMFP program used for the C6 breakthrough experiment.

Figure 7 shows a typical breakthrough experiment.

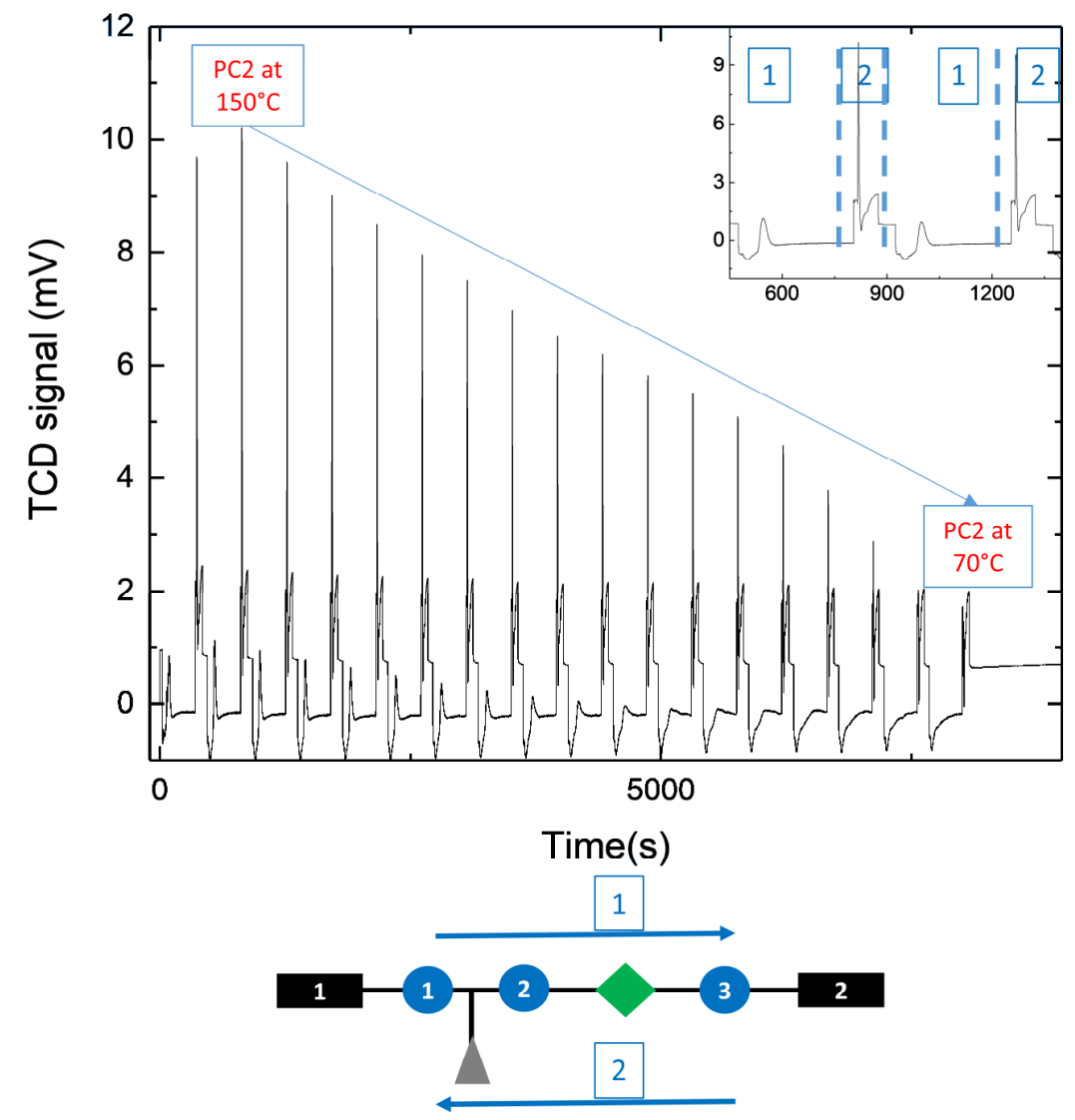

Figure 7: Breakthrough curve of $1 \mathrm{ppm} n$-hexane in nitrogen. The baseline drift and its offset were corrected. Every intense peak observed at step 2 showed the movement of $C 6$ to $\mu P C 1$ from $\mu P C 3$, meaning breakthrough occurred. See the inset: the peak observed at $545 \mathrm{~s}$ was the breakthrough of $\mathrm{C} 6$ through $\mu P C 2$ at $150^{\circ} \mathrm{C}$ during step 1 . The peak observed at $817 \mathrm{~s}$ was the return of $C 6$ from $\mu P C 3$ to $\mu P C 1$ during step 2. Every time step 1 was repeated, $\mu P C 2$ temperature was lowered by $5^{\circ} \mathrm{C}$.

273 Figure 7 shows that breakthrough happened over a wide range of temperatures, as evidenced by a 274 peak observed during step 1. The peak observed during step 2 was a second proof of a breakthrough: 
if it appeared, it meant $\mathrm{C} 6$ came back to $\mu \mathrm{PC} 1$ from $\mu \mathrm{PC} 3$. It was only possible if $\mathrm{C} 6$ managed to reach $\mu \mathrm{PC} 3$ during step 1 and went through $\mu \mathrm{PC} 2$.

As temperature of $\mu \mathrm{PC} 2$ was decreased during the experiment, breakthrough became less pronounced. This breakthrough efficiency loss is shown in step 2: the peak observed during step 2 became less and less intense. For low temperatures, breakthrough did not occur and there was no peak observed during step 2, such as, in the $\mathrm{C} 6$ case shown on Figure 7, the steps done below $75^{\circ} \mathrm{C}$. During this experiment, the setup was not opened, meaning only a single sample was loaded and then travelled during the duration of the whole experiment.

For several alkanes the experiment did not yield values for every temperature in the range, as the BV was too high compared to the volume pumped through the $\mu \mathrm{PC}$. BV values were normalized by subtracting the dead volume, measured at the start of every experiment by doing a breakthrough at $180^{\circ} \mathrm{C}$ with the sample. At this temperature, analytes were not retained on the adsorbent. Data were then fitted according to Kroupa et al. ${ }^{29}$. They proposed a two or three parameters model for the dependence of the BV with the temperature. One of the parameters is directly related to the adsorption enthalpy of the compound on the adsorbent, which is an intrinsic characteristic of the compound/adsorbent interaction.

Figure 8 shows the measured breakthrough volume for $\mathrm{C6}, \mathrm{C7}, \mathrm{C} 8$ and $\mathrm{C9}$.

a)

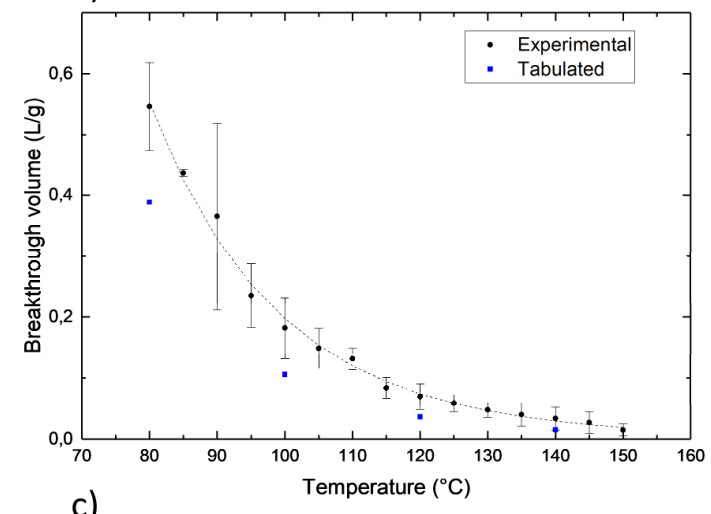

c)

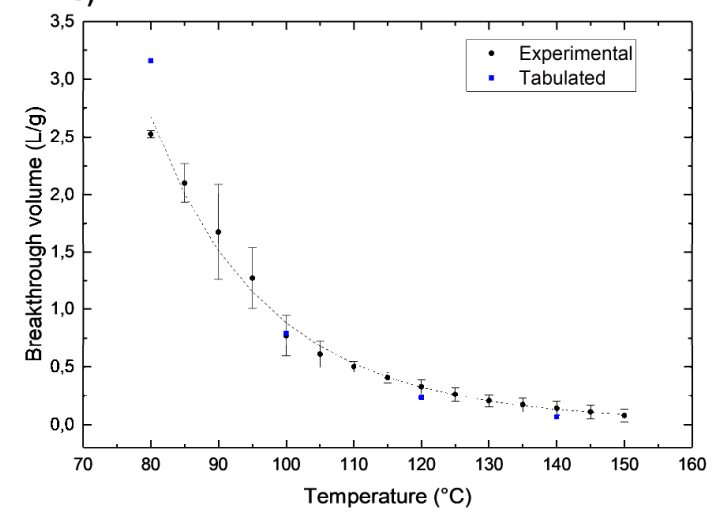

b)

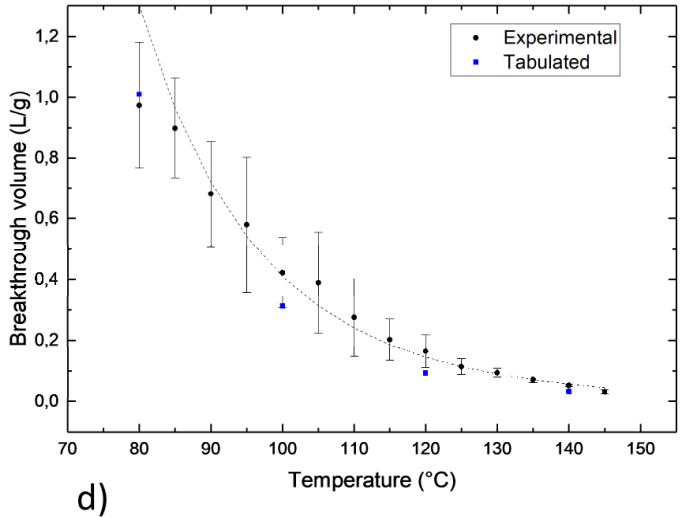

d)

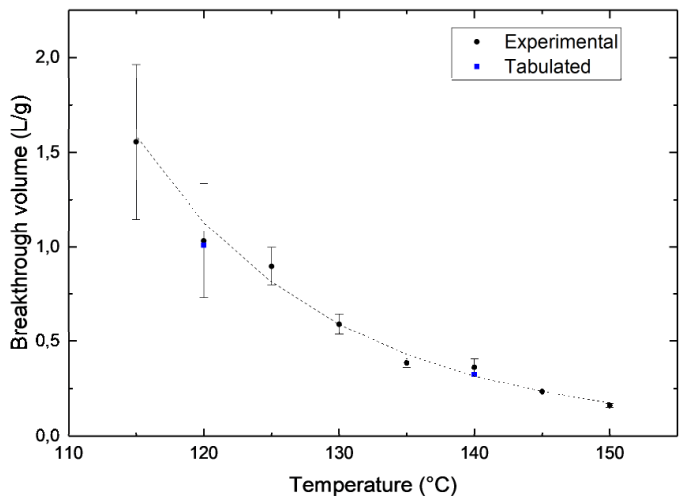

Figure 8 shows that the fit, according to the model proposed by Kroupa et al. ${ }^{29}$, of the BV as a function of the temperature was in good agreement with the measured data for all of the analysed samples. It was also possible to measure the adsorption enthalpy of $\mathrm{C} 6$ on Tenax at $25^{\circ} \mathrm{C}$ : the measured value of 
$-46.8 \pm 15.0 \mathrm{~kJ} / \mathrm{mol}$ was in the same order of magnitude as the value of $-23.8 \mathrm{~kJ} / \mathrm{mol}$ obtained by Kroupa et $\mathrm{al}^{29}$.

Data were also compared with tabulated values found on SIS website ${ }^{30}$ : a slight deviation was observed from tabulated values. This deviation was consistent with Kroupa et al. findings ${ }^{29}$ : they attributed the deviation to a fitting error in SIS interpolations.

\section{Conclusion}

The digital microfluidic platform presented in this study allows step by step programmable digital manipulations of gas samples without losses. All elementary operations (trapping/releasing, moving, mixing, and separating samples) have been demonstrated using $n$-hexane to $n$-nonane alkanes. Moreover, by programming a succession of elementary operations, it is possible to perform more complex operations and applications. This could be a first step towards digital chromatography, since the elementary operations performed by the DMFP presented here can be related to a single theoretical plate as in Martin and Synge theory ${ }^{31}$. As a first illustration, the measurements of breakthrough volumes of gases have been performed. The results were in agreement with the tabulated values obtained with standard laboratory instruments, and showed good agreement with fundamental values, such as the adsorption enthalpy of the gases on the adsorbent.

Beyond this first DMFP made of three $\mu$ PC, other DMFP with more complex network of $\mu$ PC could be developed in the future. With the development of a more complex DMFP and gas manipulation algorithm, this work could lead to new miniaturized digital systems and methods for gas sample preparation and analysis. These new methods of sample handling would be suitable for portable gas analysis systems, but also conventional gas analysis systems. For example, a digital sample handler could be used to extract compounds within a certain volatility range from a gas sample prior to injection in a conventional gas chromatograph. As another example, a system similar to the DMFP presented here could be used as an online miniaturized trap for chromatographic applications in a similar fashion to thermal modulators for comprehensive bi-dimensional gas chromatography.

\section{Bibliography}

1 M. G. Pollack, V. K. Pamula, V. Srinivasan and A. E. Eckhardt, Expert Rev. Mol. Diagn., 2011, 11, 393-407.

2 M. Ibrahim and K. Chakrabarty, Proc. IEEE, 2018, 106, 1717-1743.

3 Y. Fouillet, D. Jary, C. Chabrol, P. Claustre and C. Peponnet, Microfluid. Nanofluidics, 2008, 4, 159165.

4 R. B. Fair, Microfluid. Nanofluidics, 2007, 3, 245-281.

5 S.-Y. Teh, R. Lin, L.-H. Hung and A. P. Lee, Lab. Chip, 2008, 8, 198.

6 F. Mugele and J.-C. Baret, J. Phys. Condens. Matter, 2005, 17, R705-R774.

7 A. Wego, S. Richter and L. Pagel, J. Micromechanics Microengineering, 2001, 11, 528.

8 C. D. Chin, V. Linder and S. K. Sia, Lab Chip, 2007, 7, 41-57.

9 P. Yager, T. Edwards, E. Fu, K. Helton, K. Nelson, M. R. Tam and B. H. Weigl, Nature, 2006, 442, 412-418.

10 A. Manz, N. Graber and H. M. Widmer, Sens. Actuators B Chem., 1990, 1, $244-248$.

11 R. Malk, Y. Fouillet and L. Davoust, Sens. Actuators B Chem., 2011, 154, 191-198.

12 M. G. Pollack, A. D. Shenderov and R. B. Fair, Lab. Chip, 2002, 2, 96-101.

13 V. Srinivasan, V. K. Pamula and R. B. Fair, Anal. Chim. Acta, 2004, 507, 145-150.

14 Y. Zhao and S. K. Cho, Lab Chip, 2007, 7, 273-280.

15 P. Garstecki, I. Gitlin, W. DiLuzio, G. M. Whitesides, E. Kumacheva and H. A. Stone, Appl. Phys. Lett., 2004, 85, 2649-2651. 
16 M. Li, S. Biswas, M. H. Nantz, R. M. Higashi and X.-A. Fu, Sens. Actuators B Chem., 2013, 180, 130136.

17 M.-S. Chae, J. Kim, Y. Yoo, J. Kang, J. Lee and K. Hwang, Sensors, 2015, 15, 18167-18177.

18 B. Alfeeli and M. Agah, IEEE Sens. J., 2009, 9, 1068-1075.

19 J. J. Van Deemter, F. J. Zuiderweg and A. van Klinkenberg, Chem. Eng. Sci., 1956, 5, 271-289.

20 T. H. Chappuis, B. A. Pham Ho, M. Ceillier, F. Ricoul, M. Alessio, J.-F. Beche, C. Corne, G. Besson, J. Vial, D. Thiébaut and B. Bourlon, J. Breath Res., 2018, 12, 046011.

21 B. Bourlon, B.-A. P. Ho, F. Ricoul, T. Chappuis, A. B. Comte, O. Constantin and B. Icard, in SENSORS, 2016 IEEE, IEEE, 2016, pp. 1-3.

22 M. Akbar and M. Agah, J. Microelectromechanical Syst., 2013, 22, 443-451.

23 B. Alfeeli, V. Jain, R. K. Johnson, F. L. Beyer, J. R. Heflin and M. Agah, Microchem. J., 2011, 98, 240245.

24 B. Alfeeli, L. T. Taylor and M. Agah, Microchem. J., 2010, 95, 259-267.

25 F. Feng, B. Tian, L. Hou, Z. Yu, H. Zhou, X. Ge and X. Li, in 2017 19th International Conference on Solid-State Sensors, Actuators and Microsystems (TRANSDUCERS), 2017, pp. 1433-1436.

26 S. Narayanan and M. Agah, J. Microelectromechanical Syst., 2013, 22, 1166-1173.

27 C. G. J. Schabmueller, M. Koch, M. E. Mokhtari, A. G. R. Evans, A. Brunnschweiler and H. Sehr, J. Micromechanics Microengineering, 2002, 12, 420.

28 K. Nachef, F. Marty, E. Donzier, B. Bourlon, K. Danaie and T. Bourouina, J. Microelectromechanical Syst., 2012, 21, 730-738.

29 A. Kroupa, J. Dewulf, H. Van Langenhove and I. Víden, J. Chromatogr. A, 2004, 1038, 215-223.

30 Hydrocarbon Breakthrough Volumes for Adsorbent Resins, https://www.sisweb.com/index/referenc/bv-hyd.htm. 31 A. J. Martin and R. L. Synge, Biochem. J., 1941, 35, 1358. 